\title{
Estrutura de capital, dividendos e juros sobre o capital próprio: testes no Brasil ${ }^{1}$
}

\section{Capital structure, dividends and interests . on equity: tests in Brazil}

\author{
Mariano Seikitsi Futema \\ Consultor da FGV-Projetos • E-mail: futema@terra.com.br
}

Leonardo Fernando Cruz Basso

Professor Titular do Departamento de Economia do Centro de Ciências Sociais e Aplicadas da Universidade Presbiteriana Mackenzie

- E-mail: leonardobasso@mackenzie.br

Eduardo Kazuo Kayo

Professor Associado do Departamento de Administração da Faculdade de Economia, Administração e Contabilidade da Universidade de São Paulo・E-mail: kayo@usp.br

Recebido em 08.08.2007 • Aceito em 21.01.2008 • 2a versão aceita em 18.03.2009

\section{RESUMO}

A estrutura de capital e os dividendos são dois dos temas mais estudados em finanças corporativas. Em 2002, Fama e French estudaram esses dois temas simultaneamente dentro do contexto das teorias de tradeoff estática e pecking order. A análise conjunta significa reconhecer que o dividendo afeta a estrutura de capital e vice-versa, o que gera um problema de endogeneidade. Estendendo o estudo de Fama e French e adaptando a análise para a realidade brasileira com a inclusão de mais uma variável dependente, os juros sobre o capital próprio, o objetivo deste artigo é analisar as relações conjuntas da estrutura de capital, dividendos e juros sobre o capital próprio das empresas brasileiras para o período de 1995 a 2004. Em linhas gerais, os resultados confirmam boa parte das previsões das teorias, embora a distribuição de lucros no Brasil ainda seja muito baixa, comparada com a americana. A lucratividade demonstrou ser a variável explicativa de maior peso e influência tanto para a distribuição de lucros como para a alavancagem.

Palavras-chave: Estrutura de capital. Dividendos. Juros sobre capital próprio.

\section{ABSTRACT}

Capital structure and dividends have been frequently studied in corporate finance. In 2002, Fama and French simultaneously analyzed these two subjects in the context of tradeoff and pecking order theories. The simultaneous analysis means acknowledging that dividend influences capital structure and vice versa, leading to an endogeneity problem. Extending and adapting Fama and French's study to the Brazilian environment and including yet another dependent variable, i.e. interest on equity, this article aims to analyze the relationship among capital structure, dividends and interest on equity in the context of Brazilian companies. The analysis comprises the period from 1995 to 2004. Results corroborate many of the predictions of tradeoff and pecking order theories, despite the fact that dividend payout in Brazil is low. when compared to the United States. Profitability was the most significant variable in explaining dividend and leverage.

Keywords: Capital structure. Dividends. Interest on equity.

1 Artigo apresentado no $31^{\circ}$ EnANPAD, Rio de Janeiro-RJ, 2007. 


\section{INTRODUÇÃO}

Desde as paradigmáticas proposições de Modigliani e Miller (1958, 1963), muitas correntes ajudaram a construir um sólido arcabouço teórico sobre a Estrutura de Capital. Se, por um lado, Modigliani e Miller defendem a irrelevância da estrutura de capital para explicar o valor das empresas, por outro lado, diversas teorias, como a do tradeoff, da agência, do pecking order etc., sugerem que a forma como as empresas se financiam é, de fato, relevante. A exemplo da estrutura de capital, Miller e Modigliani (1961), também, defendem que a política de dividendos, igualmente, seria irrelevante para a criação de valor econômico.

Evidentemente, as proposições de Miller e Modigliani (1961), bem como as de Modigliani e Miller (1958, 1963), são construídas sobre a premissa de um mercado perfeito, no qual, entre outros fatores, não haveria tributação sobre os dividendos. No Brasil, no entanto, a situação (em 2006) é favorável aos dividendos por não haver tributação na sua distribuição, enquanto os ganhos de capital estão sujeitos, na maior parte dos casos, à alíquota de $15 \%$. Registre-se, entretanto, que embora a situação atual seja favorável para a distribuição de dividendos, a história brasileira testemunha muitos períodos em que os dividendos foram tributados. No Brasil, a tributação sobre os dividendos acontecia até o ano de 1995 (que coincide com o primeiro ano do período analisado no presente estudo). De 1996 a 2004 (último ano do período analisado), os dividendos não sofreram tributações relativas ao imposto de renda. Do ponto de vista teórico, essa mudança na legislação tributária poderia ocasionar uma mudança na preferência do investidor em relação ao recebimento de dividendos, influenciando, pois, os resultados da presente pesquisa. Entretanto, como a tributação aconteceu apenas no primeiro ano do estudo (dentre 10 anos analisados), esse efeito acaba sendo diluído na análise.
A maior tributação, nos EUA, dos dividendos em relação ao ganho de capital é um dos principais argumentos da escola dos que acham que os dividendos são desfavoráveis para os investidores. Para os defensores dessa linha de pensamento, os investidores reagem reduzindo mais do que proporcionalmente o preço das ações das empresas que pagam dividendos em relação às que não pagam. Como já mencionado, tal argumento não é válido no Brasil em virtude da não tributação dos dividendos. Outro ponto importante é a desvantagem temporal no pagamento dos impostos sobre os dividendos, em relação aos impostos sobre o ganho de capital, mesmo supondo as mesmas alíquotas para as duas alternativas. No ganho de capital, tal pagamento só ocorre na realização do ganho, ou seja, na venda da ação, enquanto sobre os dividendos os impostos são devidos no momento do seu recebimento. Por outro lado, como será visto, a seguir, para os investidores isentos de tributação - caso dos fundos de pensões - essa desvantagem não existe o que torna a questão da política de dividendos ainda mais controversa. Ainda no caso Brasil, outra questão importante foi a introdução dos juros sobre o capital próprio como forma alternativa para a distribuição de lucros. Os juros sobre o capital próprio podem ser interpretados como sendo dividendos com a vantagem de serem dedutíveis do imposto de renda e contribuição social.

O objetivo deste artigo é realizar uma análise conjunta da estrutura de capital, dividendos e juros sobre o capital próprio das empresas brasileiras para o período de 1995 a 2004 comparando os seus resultados com as previsões estabelecidas pelas teorias de tradeoff estática e pecking order, seguindo o modelo proposto por Fama e French (2002). Ressalte-se que, em razão da natureza não probabilística da amostra utilizada neste trabalho, os resultados aqui encontrados não devem ser generalizados para todas as empresas brasileiras. 


\section{REFERENCIAL TEÓRICO}

\subsection{Dividendos}

Lintner (1956) desenvolveu um modelo que descreve o comportamento dos dividendos. Esse modelo possui, conforme Silva e Brito (2004), três premissas relevantes para a política de dividendos: (i) assume que para a administração da empresa a estabilidade dos dividendos deve ser privilegiada, porque isso é reconhecido pelo mercado; (ii) o determinante mais importante para qualquer mudança na distribuição de dividendos é o lucro e (iii) a política de dividendos é decidida $a$ priori e as outras decisões são tomadas após a de dividendos. Com base nesse modelo, Fama e French (2002) desenvolveram a seguinte equação, em que $\mathrm{D}_{\mathrm{t}+1}$ representa os dividendos; $\mathrm{Y}_{\mathrm{t}+1} \mathrm{o}$ lucro líquido; $\mathrm{A}_{\mathrm{t}+1} \mathrm{o}$ ativo total ajustado e $\varepsilon_{t+1}$ o termo de erro.

$$
D_{t+1} / A_{t+1}=a_{0}+a_{1}^{*}\left(Y_{t+1} / A_{t+1}\right)+\varepsilon_{t+1}
$$

O coeficiente $a_{1}$ obtido é o índice desejável de distribuição de lucros (TP). Nessa equação, a distribuição de dividendos é função apenas do lucro líquido. Vale observar que a premissa assumida por Fama e French (2002) - de que o índice TP desejável é o praticado pelas empresas - decorre da baixa velocidade de ajustamento no pagamento dos dividendos, conforme constatado nas pesquisas realizadas por Lintner (1956), Fama e Babiak (1968) e Choe (1990), apud Fama e French (2002). Tais resultados reforçam a validade das premissas do modelo de Lintner (1956). A equação 1 considera apenas o lucro líquido como única variável independente, porém, outras variáveis, também, influenciam a distribuição de dividendos. Fama e French (2002) refletem isso na equação 2, a seguir, na qual $V_{t}$ representa o valor da empresa; $E_{t}$ o lucro líquido antes itens extraordinários e após IR e CSLL; o $\ln \left(\mathrm{A}_{\mathrm{t}}\right)$ logaritmo do ativo total ajustado; $\mathrm{TL}_{\mathrm{t}+1}$ a meta de alavancagem; $\mathrm{dA}_{\mathrm{t}}$ a variação do ativo total ajustado.
$D_{t+1} / A_{t+1}=a_{0}+\left(a_{1}+a_{1 V} V_{t} / A_{t}+a_{1 E} E_{t} / A_{t}+\right.$

$\left.a_{1 S} \ln \left(A_{t}\right)+a_{1 L} T L_{t+1}+a_{1 A} d A_{t} / A t_{+1}\right)$

$* Y_{t+1} / A_{t+1}+\varepsilon_{t+1}$

Nessa equação 2, o coeficiente do lucro líquido $\left(a_{1}\right)$ é afetado pela interação com as outras variáveis determinantes selecionadas. Note-se que a equação 2 tem a meta de alavancagem, TL, como uma das variáveis independentes, estimada na forma reduzida, isto é, sem levar em conta a meta de distribuição de dividendos, TP, para se evitar o problema da endogeneidade. Os coeficientes das regressões são estimados para cada ano considerando todas as empresas. O coeficiente $\left(a_{1}\right)$ - índice TP com as interações das variáveis selecionadas - é o resultado da soma das multiplicações internas aos parênteses da equação. O coeficiente final estimado é a média anual dos coeficientes. Utilizou-se o valor de mercado da empresa, $\mathrm{V}_{\mathrm{t}}$ como uma proxy das expectativas de crescimento da empresa. Na literatura financeira, o valor de mercado é considerado, muitas vezes, como uma aproximação do Q de Tobin, por incluir as oportunidades de crescimento, além da lucratividade corrente. Eventuais alterações no valor de mercado da empresa podem ser atribuídas às novas informações sobre as suas expectativas futuras que chegam ao mercado. A previsão de que a distribuição de lucros varia positivamente com as oportunidades de crescimento é fundamentada na teoria de tradeoff estática, a qual afirma que, mantida a lucratividade constante, as empresas com maiores oportunidades de investimento rentáveis pagam mais dividendos e têm menor alavancagem contábil. A lucratividade dos ativos existentes é considerada mediante a variável $\mathrm{E}_{\mathrm{t}}$ Observese que os lucros são antes dos resultados dos itens extraordinários e após o imposto de renda e contribuição social sobre o lucro líquido, da mesma forma que Silva e Brito (2004). Diferentemente de Fama e French (2002), os lu- 
cros são após os juros, pois o entendimento é que a distribuição de dividendos é afetada pelos juros. A proxy usada para a volatilidade é o tamanho da empresa expressa pelo logaritmo natural do ativo total ajustado, $\ln \left(\mathrm{A}_{\mathrm{t}}\right)$. Fama e French (2002) reconhecem que o tamanho pode ser, também, proxy de idade da empresa e facilidade de acesso ao crédito. Entretanto, para aqueles autores, o uso dessa proxy não produz ruídos maiores que outras alternativas porque as empresas com maiores ativos totais tendem a ser menos voláteis nos seus lucros e fluxos de caixa. Os investimentos são capturados pela variação do ativo total ajustado, $\mathrm{dA}_{\mathrm{t}}$. Vale notar que, enquanto o valor da empresa, $\mathrm{V}_{\mathrm{t}}$, reflete as oportunidades futuras de investimentos e a lucratividade dos ativos existentes, a variável $\mathrm{dA}_{\mathrm{t}}$, mostra apenas os investimentos efetivamente realizados no período.

A primeira hipótese a ser testada é a de que os índices de distribuição de lucros, na forma de dividendos e de juros sobre o capital próprio, variam negativamente com os investimentos e positivamente com as oportunidades de crescimento e lucratividade. Essa hipótese 1 é testada por meio das equações 1 e 2 , ou seja, na forma reduzida e na forma estrutural considerando as interações das variáveis determinantes selecionadas, respectivamente. Adicionalmente, a hipótese 1, também, é testada levando-se em consideração a inclusão dos juros sobre o capital próprio na variável dependente. Assim, são testados modelos adicionais tendo como variável dependente os juros sobre o capital próprio, $\mathrm{J}_{\mathrm{t}}$, e o somatório dos dividendos com os juros sobre o capital próprio, $\mathrm{D}_{\mathrm{t}}+\mathrm{J}_{\mathrm{t}}$.

A segunda hipótese a ser testada é a de que as metas de dividendos e de juros sobre o capital próprio são ajustadas para absorver as variações de curto prazo dos investimentos. Para testar essa hipótese deve ser lembrado, conforme Lintner (1956), que o ajuste dos dividendos na direção do índice desejável de distribuição de lucros, na maioria das empresas não é feito rapidamente. Esse ajustamento é bastante influenciado pela sinalização implícita na política de dividendos. Lintner (1956) formulou as seguintes equações, chamadas, neste trabalho, de auxiliares, para o seu modelo de política de dividendos. A $1^{\text {a }}$ equação auxiliar é apresentada na equação 3 , em que $\mathrm{TD}_{\mathrm{t}+1}$ representa a meta de dividendos para $\mathrm{t}$ +1 ; TP o índice desejável de distribuição do lucro e $\mathrm{Y}_{\mathrm{t}+1}$ o lucro líquido em $\mathrm{t}+1$.

$T D_{t+1}=T P * Y_{t+1}$

A $1^{\text {a }}$ equação relaciona o dividendo com o lucro líquido do ano e com o índice desejável de distribuição do lucro, TP. Como o ajustamento não ocorre imediatamente, pelas razões acima apontadas, Lintner (1956) formulou a $2^{\text {a }}$ equação, mostrada a seguir, em que: $D_{t+1}$ representa os dividendos para o ano $t+1 ; D_{t}$ os dividendos para o ano t; $\mathrm{SOA}$ a velocidade de ajustamento; $\mathrm{TD}_{\mathrm{t}+1}$ a meta de dividendos para $o$ ano $t+1$ e $\varepsilon_{t+1}$ o termo de erro.

$D_{t+1}-D_{t}=S O A *\left(T D_{t+1}-D_{t}\right)+\varepsilon_{t+1}$

Note-se que, se a velocidade de ajustamento, SOA, for igual a um, isto é, imediata, então os dividendos no ano $t+1$ serão iguais à meta de dividendos. Em razão da existência de custos para o ajustamento, como constatado por Lintner (1956), é de se esperar que SOA seja menor que um.

Para testar a hipótese 2, Fama e French (2002) basearam-se na $2^{\text {a }}$ equação auxiliar de Lintner (1956), incluíram a variável determinante relacionada aos investimentos e formularam a equação 5 , a seguir, em que $\mathrm{D}_{t+1}$ e $\mathrm{D}_{\mathrm{t}}$ representam os dividendos, $\mathrm{Y}_{\mathrm{t}+}$ o lucro líquido, $\mathrm{dA}_{\mathrm{t}+1}$ a variação do ativo total ajustado, $\mathrm{A}_{\mathrm{t}+1} \mathrm{o}$ ativo total ajustado e $\varepsilon_{t+1}$ o termo de erro.

$\left(D_{t+1}-D_{t}\right) / A_{t+1}=a_{0}+a_{1} Y_{t+1} / A_{t+1}+$ $a_{2} D_{t} / A_{t+1}+a_{3} d A_{t+1} / A_{t+1}+\varepsilon_{t+1}$

A equação 5 é uma regressão da variação dos dividendos contra o lucro, os dividendos 
do ano anterior e os investimentos realizados. Os coeficientes $\mathrm{a}_{3}$, estimados nas regressões, permitirá identificar se os investimentos são significativos na variação dos dividendos de um ano para outro, possibilitando testar a hipótese 2. Cabe ressaltar que, a exemplo da regressão da equação 1 , a equação 5 não captura a influência das variáveis lucratividade, oportunidade de investimentos, volatilidade e alavancagem. A interação com essas variáveis é feita na equação 6 , a seguir, em que: $D_{t+1}$ e $D_{t}$ representam os dividendos; $V_{t}$ o valor da empresa; $\mathrm{E}_{\mathrm{t}} \mathrm{o}$ lucro antes itens extraordinários e após IR e CSLL; dA variação do ativo total ajustado; $\ln \mathrm{A}_{t}$ o logaritmo natural do ativo total ajustado; $\mathrm{TL}_{\mathrm{t}+1}$ meta de alavancagem; $\mathrm{Y}_{\mathrm{t}+1} \mathrm{O}$ lucro líquido; $\mathrm{A}_{\mathrm{t}+1} \mathrm{o}$ ativo total ajustado e $\varepsilon_{\mathrm{t}+1}$ o termo de erro.

$\left(D_{t+1}-D_{t}\right) / A_{t+1}=a_{0}+\left(a_{1}+a_{1 V} V_{t} / A_{t}+\right.$ $\left.a_{1 E} E_{t} / A_{t}+a_{1 A} d A_{t} / A_{t}+a_{1 S} \ln A_{t}+a_{1 L} T l_{t+1}\right)$

$* Y_{t+1} / A_{t+1}+\left(a_{2}+a_{2 V} V_{t} / A_{t}+a_{2 E} E_{t} / A_{t}+\right.$ $\left.a_{2 A} d A_{t} / A_{t}+a_{2 S} \ln A_{t}+a_{2 L} T l_{t+1}\right) * D_{t} / A_{t+1}+$ $a_{3} d A_{t+1} / A_{t+1}+\varepsilon_{t+1}$

As equações 5 e 6 permitem o cálculo da velocidade de ajustamento no pagamento de dividendos, SOA, que conforme Fama e French (2002) é igual ao coeficiente $\mathrm{a}_{2}$, multiplicado por menos um e o índice desejável de distribuição de dividendos, TP, pode ser obtido com a divisão das médias dos coeficientes $a_{1}$ e $a_{2}$. Os coeficientes $a_{1}$ e $a_{2}$ são as médias anuais cross-section das equações 5 e 6 acima. A diferença entre as equações 5 e 6 é que a primeira não considera as alterações de TP e SOA entre as empresas, o que é capturado na segunda equação. A equação 6 permite regredir a variação dos dividendos do ano $t+1$ contra três variáveis independentes. São elas: (1) os lucros do ano $t+1$; (2) os dividendos do ano $t$, ambas afetadas com a interação das variáveis de lucratividade, oportunidades de investimentos, volatilidade, investimentos realizados e metas de alavancagem e (3) investimentos realizados.
Fama e French (2002) lembram, ainda, que o principal foco das equações 5 e 6 é estimar o coeficiente $a_{3}$ que retrata a influência do investimento nos dividendos. Não obstante seja calculado, argumentam aqueles autores que o índice TP estimado não é adequado para que sejam realizadas inferências, pois ele depende de muitos coeficientes como o do lucro, $\mathrm{Y}_{\mathrm{t}}$, do dividendo do ano anterior, $\mathrm{D}_{\mathrm{t}}$, e das interações com as variáveis determinantes selecionadas, o que dificulta a sua interpretação.

Adicionalmente, como acontece com os testes da hipótese 1 , a hipótese 2, também, é testada levando-se em consideração a inclusão dos juros sobre o capital próprio na variável dependente. Assim, são testados modelos adicionais tendo como variável dependente os juros sobre o capital próprio, $\mathrm{J}_{\mathrm{t}}$, e o somatório dos dividendos com os juros sobre o capital próprio, $\mathrm{D}_{\mathrm{t}}+\mathrm{J}_{\mathrm{t}}$.

\subsection{Estrutura de capital}

A terceira hipótese a ser testada é a de que as alavancagens das empresas se comportam da forma prevista pelas teorias de tradeoff $e$ pecking order. Dada a possibilidade de se distribuírem os lucros no Brasil, basicamente, de duas formas, adotou-se, neste artigo, a notação $\mathrm{TPD}_{\mathrm{t}}$ para representar o índice de distribuição de dividendos e TPJ t para o índice de distribuição de juros sobre o capital próprio. Para testar a hipótese 3, Fama e French (2002) desenvolveram a equação 7 que regride o endividamento $\left(\mathrm{L}_{\mathrm{t}+1}\right)$ contra as variáveis oportunidades de crescimento $\left(\mathrm{V}_{\mathrm{t}}\right)$, lucratividade $\left(\mathrm{ET}_{\mathrm{t}}\right)$, volatilidade $\left(\ln \mathrm{A}_{\mathrm{t}}\right)$, investimento $\left(\mathrm{dA}_{\mathrm{t}}\right)$ e índice de distribuição de lucros (alternadamente $\mathrm{TPD}_{\mathrm{t}+1}, \mathrm{TPJ}_{\mathrm{t}+1}$ e $\mathrm{TPD}_{\mathrm{t}+1}+\mathrm{TPJ}_{\mathrm{t}+1}$ ).

$L_{t+1} / A_{t+1}=b_{0}+b_{1} V_{t} / A_{t}+b_{2} E T_{t} / A_{t}+$ $b_{3} \ln A_{t}+b_{4} d A_{t} / A_{t}+b_{5} T P D_{t+1}+\varepsilon_{t+1}$

A meta de distribuição de dividendos, TPD, é obtida na estimativa da equação 1 . Com exceção de lucratividade, as demais variáveis são as mesmas utilizadas nas regressões anteriores. 
A variável lucratividade utilizada, da mesma forma que Silva e Brito (2004), é o lucro antes dos juros, dos itens extraordinários e após o IR e CSLL, ET, que permite levar em conta o impacto do benefício fiscal do endividamento.

No seu modelo, Fama e French (2002) assumem que os valores estimados da variável dependente de alavancagem, $\mathrm{L}_{\mathrm{t}+1} / \mathrm{A}_{\mathrm{t}+1}$, na equação 7 na forma reduzida, isto é, sem as interações com as metas de distribuição de dividendos, $\mathrm{TPD}_{\mathrm{t}}$, as metas de distribuição de juros sobre o capital próprio, TPJ, e o somatório das metas de distribuição de dividendos e juros sobre o capital próprio, $\mathrm{TPD}_{t}+\mathrm{TP}_{t^{\prime}}$ são as metas de alavancagem das empresas. Essas metas são usadas nas equações 2 e 6 . A principal observação que poderia ser feita é com relação à premissa assumida por aqueles autores de que as metas de alavancagem sejam, efetivamente, as estimadas pelas equações 7 . Note-se que essa equação regride a variável dependente de alavancagem, $\mathrm{L}_{\mathrm{t}+1}$, contra as variáveis independentes defasadas de um período (no momento $t$ ), exceto a meta de distribuição de lucros de $t+1$. A questão se os valores estimados para a variável dependente pela equação 7 se constitui realmente nas metas de alavancagem estabelecidas pela administração é respondida com os testes da hipótese 4 , na equação 8. Essa hipótese 4 testa se as empresas têm metas de alavancagem e a elas retornam. Se a hipótese 4 confirmar que as empresas têm metas de alavancagem e a elas retornam, cresce o poder de explicação da equação 7.

A quarta hipótese, por fim, é de que as empresas têm metas de alavancagem e a elas retornam. Para a hipótese 4, é necessário testar se as empresas procuram retornar para as suas metas de endividamento, mesmo com variações de curto prazo nos lucros e nos investimentos conforme prevê a teoria de tradeoff estática. Fama e French (2002) desenvolveram a equação 8 que considera tanto a meta de alavancagem como as variações nos lucros e nos investimentos. A meta de alavancagem é a estimada por meio da equação 7 . Para diferenciação nos casos de alavancagem causada por dividendos, juros sobre o capital próprio e somatório, a seguinte notação foi utilizada: $T L D_{t}$ para meta de alavancagem em função dos dividendos, $\mathrm{D}_{\mathrm{t}}$ e TLJ $J_{\mathrm{t}}$ para meta de alavancagem em função dos juros sobre o capital próprio, $\mathrm{J}_{\mathrm{t}}$.

$$
\begin{aligned}
& L_{t+1} / A_{t+1}-L_{t} / A_{t}=c_{0}+c_{1} T L D_{t+1}+ \\
& c_{2} L_{t} / A_{t}+c_{3} d E_{t+1} / A_{t+1}+c_{4} d A_{t+1} / A_{t+1}+\varepsilon_{t+1}
\end{aligned}
$$

Os coeficientes $c_{1}$ da meta de alavancagem, $\operatorname{TLD}_{\mathrm{t}+1}$, e $c_{2}$ do endividamento sobre o ativo total ajustado, $\mathrm{L}_{t} / \mathrm{A}_{\mathrm{t}}$, permitem avaliar se as empresas retornam para as suas metas. Note-se que a equação 8 regride a variação do endividamento contra a meta de endividamento $(t+1)$, o endividamento defasado $(t)$, a variação do lucro líquido e a variação do investimento. Registre-se, ainda, os resultados da pesquisa de Graham e Harvey (2001) que relataram que os diretores financeiros declararam ter metas de alavancagem, porém atingí-las não é mais importante do que aproveitar as oportunidades para emitir dívidas ou ações, conforme as condições reinantes no mercado de capitais. De forma similar, aos dividendos são feitas as regressões para se avaliar se as metas de alavancagem em função dos juros sobre o capital próprio, $\mathrm{J}_{\mathrm{t}}$ e em função do somatório dos dividendos e dos juros sobre o capital próprio, $\mathrm{D}_{\mathrm{t}}+\mathrm{J}_{\mathrm{t}}$, afetam o endividamento.

\section{PROCEDIMENTOS METODOLÓGICOS}

\subsection{Amostra e período analisado}

Foram utilizadas as informações das empresas abertas não financeiras cujas ações foram negociadas na Bolsa de Valores de São
Paulo e que tinham dados disponíveis no banco de dados da Economática, no período de 1995 a 2004. A limitação do período decorre da alta inflação presente na economia 
brasileira até 1994, que ocasionava profundos impactos tanto na atividade operacional como nas demonstrações financeiras das empresas.

As empresas selecionadas foram as que atenderam os seguintes requisitos: (1) tinham as demonstrações financeiras disponíveis para todo o período no banco de dados da Economática, ou seja, foram excluídas as empresas que abriram o seu capital após 1995; utilizou-se a demonstração financeira não consolidada das empresas; (2) pagaram, pelo menos uma vez no período, dividendos ou juros sobre o capital próprio, isto é, empresas que não pagaram aqueles proventos foram eliminadas da amostra; (3) empresas financeiras foram eliminadas da amostra, pois possuem características específicas e obedecem a legislações próprias como os bancos e as seguradoras. Com base nesses requisitos, a amostra final contou com 107 empresas.

A base de dados da Economática <www. economática.com $>$ apresenta informações coletadas de todas as empresas listadas em Bolsas de Valores nos Estados Unidos, Brasil, Argentina, Chile, México, Peru, Colombia e Venezuela contendo, entre outras, as demonstrações financeiras trimestrais, anuais, as cotações diárias das ações, os proventos, além de outras informações.

\subsection{Modelo estatístico}

Baseado no estudo de Fama e French (2002), foram desenvolvidas regressões lineares múltiplas para as seguintes variáveis dependentes: (a) índice desejável de distribuição de lucros; (b) índice de distribuição de juros sobre o capital próprio e (c) meta de alavancagem. Nesse modelo, as variáveis (a) e (b) dependem da terceira (c) e vice-versa. Isso gera um processo endógeno. A solução utilizada, recomendada por Fama e French (2002), é o uso dos resultados obtidos com a forma reduzida da equação, isto é, sem o termo endógeno. Assim, para o cálculo do índice desejável de distribuição de lucros e do índice desejável de juros sobre o capital próprio, não se considera a meta de alavancagem, vice-versa para essa última que é calculada sem os primeiros. Nas equações nas suas formas completas que incluem as interações de outras variáveis - a variável endógena é incluída, porém com os resultados obtidos na forma reduzida. De forma semelhante, as variáveis independentes escolhidas foram as mesmas utilizadas por Fama e French (2002), com exceção daquelas cujas informações não eram disponíveis em função das peculiaridades das regras contábeis e do mercado financeiro brasileiros, quais sejam: gastos com pesquisa e desenvolvimento (variável dummy, para aqueles autores) e valores de mercado de dívidas.

$\mathrm{Na}$ estimativa dos parâmetros, seguiu-se o procedimento recomendado por Fama e MacBeth (1973), isto é, para cada coeficiente estimado, foram calculados anualmente os parâmetros, por meio de uma regressão cross section, para as 107 empresas da amostra. O parâmetro final, $\bar{\alpha}_{0}$, estimado foi a média dos parâmetros anuais, conforme a equação 9 a seguir. O período $(T)$ considerado foi de nove (9) anos, embora a coleta tenha sido de dez (10) anos, porque nas equações a variável dependente é calculada para $t+1$, enquanto algumas variáveis independentes são defasadas de um ano, ou seja, são do momento t.

$$
\begin{aligned}
& \bar{\alpha}_{0}=\frac{1}{T} \sum_{t=1}^{T} \alpha_{0}, \quad t=1,2, \ldots, T ; \\
& (T=9 \text { anos })
\end{aligned}
$$

O erro padrão, ep $\left(\bar{\alpha}_{0}\right)$, foi calculado para cada um dos parâmetros, conforme a equação 10, segundo o procedimento sugerido por Fama e MacBeth (1973). Note-se que o período considerado é $\mathrm{T}^{2}$ por se tratar de média da amostra, conforme explica Cochrane (2005). A estatística $t$ de Student, equação 11, foi calculada para $n-1$ períodos, ou seja, oito (8) anos e utilizou-se o nível de significância de $5 \%$, bicaudal, para a análise dos dados. Os valores estimados dos parâmetros são signi- 
ficativos quando superiores ao módulo de 2,306 (distribuição $t_{8,0,95}$ ).

ep $\left(\bar{\alpha}_{0}\right)=\sqrt{\frac{1}{T^{2}} \sum_{t=1}^{T}\left(\alpha_{0}-\bar{\alpha}_{0}\right)^{2}}$,

$t=1,2, \ldots, T ;(T=9$ anos $)$

$t=\frac{\bar{\alpha}_{0}}{e p\left(\bar{\alpha}_{0}\right)}$

$\sim$ sob hipótese nula $t_{(T-1,1-\alpha / 2)}$

\subsection{Definição operacional das variáveis}

O Quadro 10 apresenta as variáveis estudadas, as respectivas definições operacionais e fonte dos dados. A expressão alavancagem, utilizada neste artigo, é a razão entre o endividamento $\left(\mathrm{L}_{\mathrm{t}}\right)$ e o ativo total ajustado $\left(\mathrm{A}_{\mathrm{t}}\right)$. A lucratividade é a razão entre o lucro líquido antes de itens extraordinários e após IR e CSLL, ( $\left.\mathrm{E}_{\mathrm{t}}\right)$, ou o lucro antes das despesas fi- nanceiras e dos itens extraordinários e após o IR e CSLL, $\left(E_{t}\right)$, e o ativo total ajustado $\left(A_{t}\right)$.

\subsection{Aplicação e limitação do artigo de Fama e French (2002) no Brasil}

Conforme mencionado na Introdução, o objetivo deste artigo é replicar, adaptado às condições da economia brasileira, o artigo de Fama e French (2002). As variáveis escolhidas para as regressões foram as mesmas utilizadas por aqueles autores, com exceção daquelas não disponíveis para as empresas consideradas na amostra deste trabalho, como gastos com pesquisa e desenvolvimento e valor de mercado das dívidas. A alavancagem foi pesquisada por Fama e French (2002) considerando os valores de mercado e os valores contábeis das dívidas. Em razão da quase total inexistência de informações sobre o valor de mercado de dívidas das empresas, considerou-se, neste trabalho, apenas a alavancagem com base no valor con-

Quadro 1 Definição operacional das variáveis de pesquisa

\begin{tabular}{|c|c|c|c|}
\hline Notação & Variável de Pesquisa & Fórmula ou Nome na Economática & Fonte \\
\hline$A_{t}$ & Ativo Total Ajustado & $\begin{array}{l}\text { Ativo total - (Fornecedores CP + Impostos a Pagar } \\
\mathrm{CP}+\text { Dividendos a Pagar CP + Provisões CP) }\end{array}$ & Balanço Patrimonial \\
\hline$d A_{t}$ & Variação do Ativo Total Ajustado & $=$ Ativo Total Ajustado $_{t}-$ Ativo Total $_{\text {Ajustado }}{ }_{t-1}$ & Balanço Patrimonial \\
\hline$Y_{t}$ & Lucro Líquido & Lucro Líquido & DRE \\
\hline$D_{t}$ & Dividendos & Dividendos & DOAR \\
\hline$J_{t}$ & Juros Sobre o Capital Próprio & Juros Sobre Patrimônio Líquido & DRE \\
\hline$E_{t}$ & $\begin{array}{l}\text { Lucro Líquido antes de itens extra- } \\
\text { ordinários e após IR e CSLL }\end{array}$ & $\begin{array}{l}\text { = Lucro Líquido - Resultados Não Operacionais + } \\
\text { Participações e Contribuições Estatutárias + Partici- } \\
\text { pações Minoritários }\end{array}$ & DRE \\
\hline $\mathrm{dE}_{\mathrm{t}}$ & $\begin{array}{l}\text { Variação do lucro antes itens extra- } \\
\text { ordinários e após IR e CSLL }\end{array}$ & $=\mathrm{E}_{\mathrm{t}}-\mathrm{E}_{\mathrm{t}-1}$ & DRE \\
\hline $\mathrm{ET}_{\mathrm{t}}$ & $\begin{array}{l}\text { Lucro antes de juros, itens extraor- } \\
\text { dinários e após IR e CSLL }\end{array}$ & $\mathrm{E}_{\mathrm{t}}+$ Resultado Financeiro & DRE \\
\hline $\mathrm{L}_{\mathrm{t}}$ & Endividamento & $\begin{array}{l}=\text { Fin CP + Fin Moeda Estrangeira CP + Fin Moeda } \\
\text { Nacional CP + ACC + Debêntures CP + A Pagar a } \\
\text { Controladas CP + Outros Passivos CP + Exigível LP }\end{array}$ & Balanço Patrimonial \\
\hline$V_{t}$ & Valor da Empresa & $\begin{array}{l}=\text { Preço da Ação sem ajuste de proventos } \times n^{\circ} \text { de } \\
\text { ações + Endividamento }\left(L_{t}\right)\end{array}$ & $\begin{array}{l}\text { (Balanço e cotações } \\
\text { das ações ordinárias } \\
\text { e preferenciais)* }\end{array}$ \\
\hline
\end{tabular}

Legendas: CP é curto prazo; IR é imposto de renda; CSLL é contribuição social sobre o lucro líquido; Fin é financiamento; Resultado Financeiro é a diferença entre despesas e receitas financeiras. ACC é adiantamento de contrato de câmbio; DRE é Demonstração de Resultados do Exercício; DOAR é Demonstração de Origens e Aplicação de Recursos.

* Cotação de fechamento, na sua inexistência, a anterior mais próxima. 
tábil. Por outro lado, em razão da existência de juros sobre o capital próprio no Brasil, diferentemente dos EUA, foram desenvolvidas equa- ções de regressões lineares múltiplas especialmente para analisar essa variável.

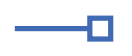

\section{ANÁLISE DOS RESULTADOS}

\subsection{Hipótese 1}

A Tabela 10 apresenta os resultados das análises de regressão da equação 1, tomandose alternadamente como variáveis dependentes os dividendos $\left(\mathrm{D}_{\mathrm{t}+1} / \mathrm{A}_{\mathrm{t}+1}\right)$, os juros sobre o capital próprio $\left(\mathrm{J}_{\mathrm{t}+1} / \mathrm{A}_{\mathrm{t}+1}\right)$ e a somatória dos dois tipos de distribuição de lucros $\left(\mathrm{D}_{\mathrm{t}+1} / \mathrm{A}_{\mathrm{t}+1}\right.$ $\left.+\mathrm{J}_{\mathrm{t}+1} / \mathrm{A}_{\mathrm{t}+1}\right)$.

O índice de distribuição de lucros, TP, que é o coeficiente $a_{1}$, varia de 0,07 no caso dos juros sobre o capital próprio, $\mathrm{J}_{\mathrm{t}}$ até 0,187 para o somatório dos dividendos e juros sobre o capital próprio, $\mathrm{D}_{\mathrm{t}}+\mathrm{J}_{\mathrm{t}^{\circ}}$ Os resultados são significativos como indicam todas as estatísticas $t$ obtidas, muito superiores à estatística $t$ crítica para um nível de significância de 5\%, bicaudal. O $t$ crítico de 9 (nove) anos para os dividendos, $\mathrm{D}_{\mathrm{t}+1} / \mathrm{A}_{\mathrm{t}+1}$, e para o somatório dos dividendos e juros sobre o capital próprio, $\mathrm{D}_{\mathrm{t}+1} / \mathrm{A}_{\mathrm{t}+1}+\mathrm{J}_{\mathrm{t}+1} / \mathrm{A}_{\mathrm{t}+1}$, é 2,306 e de 7 (sete) anos no caso dos juros sobre o capital próprio, $\mathrm{J}_{\mathrm{t}+1} /$ $A_{t+1}$, é 2,447. Esses resultados indicam que as empresas brasileiras apresentam uma baixa de distribuição de lucros quando compara-

Tabela 1 Estimativas da equação 1

\begin{tabular}{|c|c|c|c|c|}
\hline & Intercepto & $Y_{t+1} / A_{t+1}$ & TP & $\mathbf{R}^{2}$ \\
\hline \multicolumn{5}{|l|}{$D_{t+1} / A_{t+1}$} \\
\hline Média & 0,01417 & 0,11730 & 0,11730 & 0,18576 \\
\hline Estatística t & 5,05808 & 4,55725 & & 4,57624 \\
\hline \multicolumn{5}{|l|}{$J_{t+1} / A_{t+1}$} \\
\hline Média & 0,01065 & 0,07005 & 0,07005 & 0,15147 \\
\hline Estatística t & 7,23750 & 5,27534 & & 5,67983 \\
\hline \multicolumn{5}{|c|}{$D_{t+1} / A_{t+1}+J_{t+1} / A_{t+1}$} \\
\hline Média & 0,02482 & 0,18735 & 0,18735 & 0,26343 \\
\hline Estatística t & 6,40753 & 5,20799 & & 6,68008 \\
\hline
\end{tabular}

dos com os encontrados por Fama e French (2002) que reportaram 0,46. Entretanto, são superiores aos encontrados por Silva e Brito (2004) que relataram um índice de 0,11 para o período de 1995 a 2001. Também é relevante destacar o $\mathrm{R}^{2}$ do somatório dos dividendos e juros sobre o capital próprio, $\mathrm{D}_{\mathrm{t}}+\mathrm{J}_{\mathrm{t}}$, de 0,26 , dado o seu baixo valor encontrado nas regressões cross section, como afirmam Fama e French (2002) que obtiveram 0,25 na sua pesquisa. Como a legislação brasileira impõe a obrigatoriedade de distribuição de lucros e o pagamento dos juros sobre o capital próprio, $\mathrm{J}_{\mathrm{t}}$, é recente no Brasil - apenas a partir de 1997 é que as empresas passaram a pagá-lo de forma mais significativa - é razoável esperar um crescimento desse índice para o futuro.

As inclusões das variáveis de interações que afetam o lucro líquido permitem avaliar os impactos das oportunidades de crescimento, da lucratividade, da volatilidade, da alavancagem e dos investimentos na distribuição do lucro. A Tabela $2 \bullet$ traz as estimativas com os painéis $A, B$ e C. No painel A, são apresentados os valores estimados das regressões sem o termo de alavancagem, $\mathrm{TL}_{\mathrm{t}+1}$. No painel $\mathrm{B}$, é acrescentado o termo $\mathrm{TL}_{\mathrm{t}+1}$, estimado na forma reduzida da equação 7 , isto é, sem considerar TP, para se evitar o problema da endogeneidade. $\mathrm{O}$ painel $\mathrm{C}$ é uma estimativa com a omissão da variável lucratividade, $\mathrm{E}_{\mathrm{t}+1}$, em razão da suspeita de colinearidade entre ela e a alavancagem.

A inclusão de variáveis de interação, porém, sem considerar a alavancagem, TL, produziu uma pequena melhora nos índices de distribuição de lucros, TP's, atingindo 0,19 para o somatório dos dividendos e juros sobre o capital próprio, $\mathrm{D}_{\mathrm{t}}+\mathrm{J}_{\mathrm{t}}$, indicando que a lucratividade, $\mathrm{E}_{\mathrm{t}}$, é relevante, seus coefi- 
Tabela 2 Estimativas da equação 2

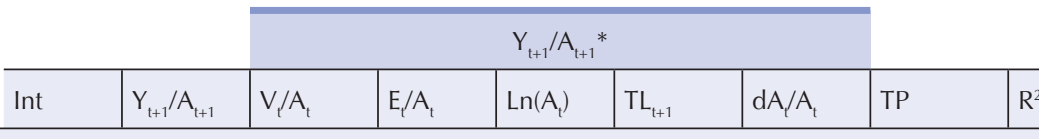

$D_{t+1} / A_{t+1}$

Painel A

\begin{tabular}{l|c|c|c|c|c|c|c|c|c}
\hline Média & 0,0103 & $-0,2260$ & 0,1125 & 0,3893 & 0,0175 & & $-0,1674$ & 0,1132 & 0,4331 \\
\hline Estatística t & 6,4460 & $-1,8875$ & 8,4536 & 2,9368 & 1,8603 & & $-1,6270$ & 12,9796 & 8,3130 \\
\hline
\end{tabular}

Painel B

\begin{tabular}{l|c|c|c|c|c|c|c|c|c}
\hline Média & 0,0104 & $-0,4102$ & $-0,0026$ & 0,6617 & 0,0217 & 0,4973 & $-0,1717$ & 0,1081 & 0,4353 \\
\hline Estatística t & 6,6059 & $-2,6241$ & $-0,0414$ & 3,4538 & 2,3647 & 2,0112 & $-1,7787$ & 11,7260 & 8,4270 \\
\hline
\end{tabular}

Painel C

\begin{tabular}{l|c|c|c|c|c|c|c|c|c}
\hline Média & 0,0105 & $-0,0907$ & 0,2197 & & 0,0165 & $-0,4507$ & $-0,1279$ & 0,1252 & 0,4119 \\
\hline Estatística t & 6,3505 & $-0,7446$ & 7,4496 & & 1,9243 & $-3,3867$ & $-1,1744$ & 15,0215 & 7,6468 \\
\hline$J_{t+\boldsymbol{t}} / \boldsymbol{A}_{\boldsymbol{t + \boldsymbol { 1 }}}$
\end{tabular}

Painel A

\begin{tabular}{l|c|c|c|c|c|c|c|c|c}
\hline Média & 0,0081 & $-0,0335$ & $-0,0085$ & 0,3443 & 0,0083 & & $-0,1016$ & 0,0771 & 0,2470 \\
\hline Estatística t & 6,4836 & $-0,7121$ & $-1,0366$ & 3,6421 & 2,0252 & & $-1,8662$ & 31,9438 & 6,5032 \\
\hline
\end{tabular}

Painel B

\begin{tabular}{l|c|c|c|c|c|c|c|c|c}
\hline Média & 0,0079 & $-0,0674$ & $-0,0503$ & 0,4694 & 0,0078 & 0,1783 & $-0,0935$ & 0,0796 & 0,2597 \\
\hline Estatística t & 5,9463 & $-0,7670$ & $-0,9542$ & 2,8002 & 1,6487 & 0,9118 & $-1,5736$ & 32,4359 & 6,0857 \\
\hline
\end{tabular}

Painel C

\begin{tabular}{l|c|c|c|c|c|c|c|c|c}
\hline Média & 0,0083 & 0,0874 & 0,0872 & & 0,0075 & $-0,4144$ & $-0,0656$ & 0,0833 & 0,2265 \\
\hline Estatística t & 6,5846 & 1,5480 & 3,2914 & & 1,6728 & $-3,5100$ & $-1,5479$ & 33,7462 & 6,4879 \\
\hline$D_{t+1} / A_{t+1}+\boldsymbol{J}_{t+1} / A_{t+1}$ \\
\hline
\end{tabular}

Painel A

\begin{tabular}{l|c|c|c|c|c|c|c|c|c}
\hline Média & 0,0184 & $-0,2595$ & 0,1040 & 0,7336 & 0,0258 & & $-0,2690$ & 0,1903 & 0,5199 \\
\hline Estatística t & 7,9112 & $-1,6476$ & 5,3895 & 3,7908 & 1,9833 & & $-2,1714$ & 19,8409 & 13,6640 \\
\hline
\end{tabular}

Painel B

\begin{tabular}{|c|c|c|c|c|c|c|c|c|c|}
\hline Média & 0,0183 & $-0,4775$ & $-0,0529$ & 1,1311 & 0,0295 & 0,6757 & $-0,2653$ & 0,1877 & 0,5272 \\
\hline Estatística t & 7,4855 & $-2,4726$ & $-0,5678$ & 3,9664 & 2,3462 & 2,0541 & $-2,2472$ & 18,7815 & 13,6184 \\
\hline \multicolumn{10}{|l|}{ Painel C } \\
\hline Média & 0,0188 & $-0,0033$ & 0,3069 & & 0,0239 & $-0,8651$ & $-0,1935$ & 0,2084 & 0,4861 \\
\hline Estatística t & 7,7315 & $-0,0235$ & 6,9831 & & 1,9905 & $-4,6209$ & $-1,6026$ & 23,8700 & 12,1623 \\
\hline
\end{tabular}


cientes são respeitáveis e, estatisticamente, significativos nos três casos. Isso se mostra consistente com a previsão da teoria de pecking order que prevê maiores dividendos em empresas mais rentáveis e, também, com a teoria de tradeoff estática que invoca fluxos de caixas livres mais altos como motivação para maiores dividendos, mantidos os investimentos constantes. Os valores das empresas, $\mathrm{V}_{\mathrm{t}}$, mostraram-se, estatisticamente, significativos apenas no caso dos dividendos, $\mathrm{D}_{\mathrm{t}}$ e no caso do somatório dos dividendos e juros sobre o capital próprio, $\mathrm{D}_{\mathrm{t}}+\mathrm{J}_{\mathrm{t}}$, embora apresentassem coeficientes relativamente baixos $(0,11$ e 0,10 , respectivamente), também confirmam a previsão da teoria de tradeoff estática. Se $\mathrm{V}_{\mathrm{t}}$ refletir no valor da empresa a lucratividade dos ativos existentes e as oportunidades de crescimento, a lucratividade estaria positivamente correlacionada com a distribuição de lucros. Já a volatilidade, $\ln \left(\mathrm{A}_{\mathrm{t}}\right)$, e o investimento, $\mathrm{dA}$, não se mostraram significativos. Novamente, os resultados estão de acordo com a premissa assumida por Lintner (1956) de que a administração privilegia a estabilidade da política de dividendos, não a alterando em função dos investimentos. Ressalte-se que, apesar de não significativos, os sinais dos coeficientes dos investimentos foram negativos para os três casos, o que é consistente com ambas as teorias.

A inclusão da meta de alavancagem, TL, no painel B mostra uma mínima redução do índice de distribuição de lucros, TP nos casos dos dividendo, $\mathrm{D}_{\mathrm{t}}$, e do somatório dos dividendos e juros sobre o capital próprio, $\mathrm{D}_{t}+\mathrm{J}_{\mathrm{t}}$ o que é consistente com a previsão de que o endividamento impõe obrigações reduzindo o fluxo de caixa livre e, consequentemente, a distribuição de lucros. Por outro lado, as oportunidades de crescimento deixam de ser significativas sinalizando que o endividamento impõe restrições ao crescimento da empresa conforme defende a teoria de pecking order. Já a lucratividade continua significativa e com coeficientes ainda maiores, confirmando a estreita relação entre ela e a distribuição de lucros, prevista nas duas teorias. A volatilidade torna-se significativa para dividendos, $\mathrm{D}_{\mathrm{t}}$, e para o somatório dos dividendos e juros sobre o capital próprio, $\mathrm{D}_{\mathrm{t}}+\mathrm{J}_{\mathrm{t}}$, embora com coeficientes baixos, o que confirma a hipótese de que empresas maiores (tamanho) podem ser mais alavancadas e manter a distribuição de lucros, enquanto os investimentos não se mostrarem significativos, mantendo, porém, o sinal negativo dos coeficientes.

No painel C, a omissão da lucratividade torna os coeficientes das oportunidades de crescimento e da alavancagem expressivos e com robustas significâncias estatísticas. A relação entre a alavancagem e a lucratividade, mantidos constantes os demais itens, é refletida no coeficiente negativo da alavancagem, conforme prevêm as teorias de tradeoff estática e pecking order. As oportunidades de crescimento tornam-se significativas nos três casos, ao contrário da volatilidade que deixa de sê-la (comparada com a equação completa, com o termo de alavancagem, TL) e do investimento que não se mostrou significativo em nenhum painel. Deve ser ressaltado o expressivo aumento do $\mathrm{R}^{2}$ provocado pela inclusão das variáveis de interação que passaram de 0,26 para 0,52 na equação completa para o somatório dos dividendos e juros sobre o capital próprio, $\mathrm{D}_{\mathrm{t}}+\mathrm{J}_{\mathrm{t}}$, aumentado o poder de explicação da equação, conforme afirmam Fama e French (2002).

Os resultados dos painéis $\mathrm{A}, \mathrm{B}$ e $\mathrm{C}$ confirmam a hipótese 1 de que a distribuição de lucros varia negativamente com os investimentos e positivamente com a lucratividade. Entretanto, a relação negativa entre as oportunidades de crescimento e a distribuição de lucros obtida com a equação completa - incluindo a alavancagem - não confirma a variação positiva prevista na teoria de tradeoff estática.

\subsection{Hipótese 2}

As estimativas da equação 5 , medindo o ajustamento dos dividendos para as variações 
Tabela 3 Estimativas da equação 5

\begin{tabular}{|c|c|c|c|c|c|c|c|}
\hline & Int & $Y_{t+1} / A_{t+1}$ & $D_{t} / A_{t+1}$ & $d A_{t+1} / A_{t+1}$ & SOA & TP & $\mathrm{R}^{2}$ \\
\hline \multicolumn{8}{|c|}{$\left(D_{t+1}-D_{t}\right) / A_{t+1}$} \\
\hline Média & 0,0040 & 0,1616 & $-0,3328$ & $-0,0158$ & 0,3328 & 0,4854 & 0,2662 \\
\hline Estatística t & 3,8765 & 2,1225 & $-4,4952$ & $-1,4674$ & & & 3,0582 \\
\hline \multicolumn{8}{|l|}{$\left(J_{t+1}-J\right) / A_{t+1}$} \\
\hline Média & 0,0045 & 0,0484 & $-0,4282$ & $-0,0063$ & 0,4282 & 0,1130 & 0,2306 \\
\hline Estatística t & 6,5056 & 9,1086 & $-6,7632$ & $-1,8855$ & & & 4,0398 \\
\hline \multicolumn{8}{|c|}{$\left(D_{t+1}-D_{t}+J_{t+1}-J\right) / A_{t+1}$} \\
\hline Média & 0,0073 & 0,1271 & $-0,3151$ & $-0,0232$ & 0,3151 & 0,4033 & 0,2759 \\
\hline Estatística t & 6,2576 & 7,5193 & $-6,6846$ & $-2,0019$ & & & 4,5729 \\
\hline
\end{tabular}

de curto prazo dos investimentos, são apresentadas na Tabela $3 \mathbf{0}$. Observe-se, porém, que as estimativas foram feitas para o conjunto das empresas não levando em consideração as velocidades de ajustamento individuais de cada empresa. Entretanto, conforme lembram Fama e French (2002), as metas de distribuição de lucros, TP, e velocidades de ajustamento variam entre as empresas. Isso é levado em conta na equação 6 , cujos resultados são apresentados na Tabela $4 \mathbf{0}$.

As estimativas das regressões demonstram que o investimento não afeta a distri- buição de lucros tanto para os dividendos, $\mathrm{D}_{\mathrm{t}}$, como para os juros sobre o capital próprio, $\mathrm{J}_{\mathrm{t}}$ e o somatório dos dividendos e juros sobre o capital próprio, $D_{t}+J_{t}$ como informam as estatísticas $t$ dos investimentos, $\mathrm{dA}_{\mathrm{t}} / \mathrm{A}_{\mathrm{t}}$, que não são significativas. Isso parece confirmar a premissa de Lintner (1956) de que a administração privilegia a estabilidade e reluta em alterar os dividendos, $\mathrm{D}_{\mathrm{t}}$, e/ou juros sobre o capital próprio, $\mathrm{J}_{\mathrm{t}}$, por causa da sinalização implícita que uma alteração na política de distribuição de lucros poderia enviar aos investidores. A distribuição de lucro do ano

Tabela 4 Estimativas da equação $\mathbf{6}$

\begin{tabular}{|c|c|c|c|c|c|c|c|}
\hline & Int & $Y_{t+1} / A_{t+1}$ & $D_{t} / A_{t+1}$ & $d A_{t+1} / A_{t+1}$ & SOA & TP & $R^{2}$ \\
\hline \multicolumn{8}{|c|}{$\left(D_{t+1}-D_{p}\right) / A_{t+1}$} \\
\hline Média & 0,0030 & 0,0785 & $-0,3121$ & $-0,0135$ & 0,3121 & 0,2516 & 0,4387 \\
\hline Estatística t & 3,2277 & 21,5164 & $-31,7482$ & $-1,8053$ & & & 5,1336 \\
\hline \multicolumn{8}{|l|}{$\left(J_{t+1}-J_{t}\right) / A_{t+1}$} \\
\hline Média & $-0,0004$ & 0,0597 & $-0,0802$ & $-0,0118$ & 0,0802 & 0,7446 & 0,2229 \\
\hline Estatística t & $-0,2515$ & 17,1786 & $-31,6028$ & $-1,2034$ & & & 2,7377 \\
\hline \multicolumn{8}{|c|}{$\left(D_{t+1}-D_{t}+J_{t+1}-J_{t}\right) / A_{t+1}$} \\
\hline Média & 0,0060 & 0,1411 & $-0,3789$ & $-0,0172$ & 0,3789 & 0,3723 & 0,4710 \\
\hline Estatística t & 7,7555 & 34,5400 & $-43,3684$ & $-2,1633$ & & & 7,0070 \\
\hline
\end{tabular}


anterior em dividendos, juros sobre o capital próprio e o somatório desses dois, $\mathrm{D}_{\mathrm{t}}, \mathrm{J}_{\mathrm{t}}$ e $\mathrm{D}_{\mathrm{t}}$ $+\mathrm{J}_{\mathrm{t}}$ e o lucro do ano são significativos - com exceção do lucro no caso $\left(D_{t+1}-D_{t}\right) / A_{t+1}$, porém com significância estatística próxima do $t$ crítico - confirmando que as empresas privilegiam a estabilidade na política de distribuição de lucros como afirma Lintner (1956). Além disso, vale notar que a velocidade de ajustamento, SOA do pagamento de dividendos, juros sobre o capital próprio e o somatório desses dois itens, refletida pelos coeficientes de $\mathrm{D}_{\mathrm{t}} / \mathrm{A}_{\mathrm{t}+1}$ é de 0,33, 0,42 e 0,31, para cada caso, respectivamente, indicando a presença de custos de ajustamento. Essa velocidade - exceção feita a juros sobre o capital próprio, $\mathrm{J}_{\mathrm{t}}$, isoladamente é comparável àquela encontrada por Fama e French de 0,33.

As inclusões das interações com as oportunidades de crescimento, lucratividade, volatilidade, alavancagem e investimentos, influindo nos coeficientes $a_{1}$ do lucro líquido e $a_{2}$ da distribuição de lucros, são reportados na Tabela 4.

A inclusão das variáveis de interação provocou um aumento na velocidade de ajustamento, SOA, de 0,31 para 0,37 do somatório da variação anual dos dividendos com a variação anual dos juros sobre o capital próprio, $\left(D_{t+1}-D_{t}+J_{t+1}-J_{t}\right) / A_{t+1}$, sugerindo que aquelas variáveis afetam o ajustamento da distribuição de lucros, embora tenha reduzido nos casos de variação dos dividendos, $\left(\mathrm{D}_{\mathrm{t}+1}-\mathrm{D}_{\mathrm{t}}\right)$ / $\mathrm{A}_{\mathrm{t}+1}$ e variação dos juros sobre o capital próprio, $\left(\mathrm{J}_{\mathrm{t}+1}-\mathrm{J}_{\mathrm{t}}\right) / \mathrm{A}_{\mathrm{t}+1}$. Ressalte-se, porém, que a distribuição do lucro com uma participação maior de juros sobre o capital próprio, $\mathrm{J}_{\mathrm{t}}$, como seria de se esperar, dadas as inequívocas vantagens fiscais, tornam as estimativas do somatório de $\mathrm{D}_{\mathrm{t}}$ com $\mathrm{J}_{\mathrm{t}}$ mais condizentes com a realidade brasileira, do que considerar $\mathrm{D}_{t}$ ou $\mathrm{J}_{\mathrm{t}}$ individualmente. Tais resultados sugerem que as empresas brasileiras tendem a caminhar para uma composição entre dividendos e juros sobre o capital próprio na distribuição de lucros. Para isso contribuem a não tributação na fonte dos dividendos, que favorece o investidor, e o benefício fiscal para a empresa que favorece os juros sobre o capital próprio. São, também, dignas de registro as expressivas melhoras nos $\mathrm{R}^{2}$ no primeiro e terceiro caso $(0,43$ e 0,47$)$ quando comparadas às estimativas sem interação, o que sugere que a inclusão das variáveis de interação aumenta o poder de explicação das regressões, como afirmam Fama e French (2002) que obtiveram $\mathrm{R}^{2}$ de 0,42 .

Novamente os resultados indicam que os investimentos não são significativos no ajustamento dos dividendos e/ou juros sobre o capital próprio. Esse resultado é coerente com a previsão da teoria de pecking order de que os dividendos são fixos e variações nos lucros e nos investimentos são absorvidas principalmente por variações na dívida. Por outro lado, embora não significativos os sinais dos coeficientes são todos negativos, confirmando a relação negativa entre distribuição de lucros e investimentos.

O principal objetivo da equação 6 , como lembram Fama e French (2002), é analisar a influência do investimento, $\mathrm{dA}_{\mathrm{t}}$, no ajustamento da distribuição dos lucros. Por essa razão, o comportamento do índice de distribuição de lucros, TP, embora seja estimado, é considerado de difícil interpretação e "sem esperanças", pois depende de "forma complicada" dos coeficientes e das variáveis de interação do lucro, $\mathrm{Y}_{\mathrm{t}}$, e da distribuição de lucros, $\left(\mathrm{D}_{\mathrm{t}}, \mathrm{J}_{\mathrm{t}}\right.$ e $\left.\mathrm{D}_{\mathrm{t}}+\mathrm{J}_{\mathrm{t}}\right)$, nas palavras de Fama e French (2002, p. 17). Em outras palavras, é preferível utilizar o índice de distribuição de lucros, TP, anteriormente estimado para H1, com e sem as interações.

\subsection{Hipótese 3}

O teste da hipótese 3 é feito regredindose o endividamento contra o valor da empresa $\left(\mathrm{V}_{\mathrm{t}}\right)$, a lucratividade $\left(\mathrm{ET}_{\mathrm{t}}\right)$, a volatilidade $\left(\ln \left(A_{t}\right)\right)$, o investimento $\left(d_{t}\right)$ e o índice de distribuição de lucros (TP). A lucratividade $\left(\mathrm{ET}_{\mathrm{t}}\right)$, que considera o lucro antes dos juros e itens extraordinários e após imposto de 
renda, reflete o resultado operacional da empresa. A teoria de pecking order prevê menor endividamento nas empresas mais rentáveis, pois elas financiam seus investimentos com os lucros retidos e só recorrem ao endividamento quando esses forem insuficientes. Por outro lado, para a teoria de tradeoff estática, os custos de agência, os benefícios fiscais e menores custos de falência, induzem as empresas mais rentáveis em direção a um maior endividamento.

Com relação aos investimentos, a versão mais simples da teoria de pecking order prevê que, mantida a lucratividade constante, empresas com maiores investimentos são mais alavancadas, enquanto a versão mais complexa prevê que as empresas com maiores expectativas de investimentos são menos alavancadas. Já a teoria de tradeoff estática prevê que, mantida a lucratividade constante, as empresas com maiores oportunidades de investimentos pagam mais dividendos e têm menor alavancagem.

$\mathrm{O}$ índice distribuição de lucros, TP, utilizado é o estimado na equação 1 , ou seja, na forma reduzida, sem a interação com a alavancagem, o que evita o problema da endogeneidade. As estimativas da equação 7 são apresentadas na Tabela $5 \boldsymbol{\theta}$, que mostra os painéis $\mathrm{A}, \mathrm{B}$ e $\mathrm{C}$. O painel $\mathrm{A}$ traz a estimativa da variável dependente, TL, na forma reduzida sem considerar o índice de distribuição de lucros, TP. O painel B traz as estimativas na forma completa. O painel C omite a variável lucratividade, em razão da suspeita de colinearidade entre ela e a alavancagem.

A estimativa do painel A é válida para as três alternativas de dividendos, juros sobre o capital próprio e somatório de dividendos dos dois, $\mathrm{D}_{\mathrm{t}}, \mathrm{J}_{\mathrm{t}}$ e $\mathrm{D}_{\mathrm{t}}+\mathrm{J}_{\mathrm{t}}$ pois é feita sem o índice de distribuição de lucros, TP. Os resultados mostram que o valor da empresa, $V_{t}$, e a lucratividade, $E T_{t}$ são significativos e com coeficientes respeitáveis, indicando que o endividamento varia negativamente com a lucratividade conforme prevê a teoria de pecking order e contrariamente à previsão da tradeoff estática. Admitindo que o valor da empresa reflita as oportunidades de crescimento e a lucratividade dos ativos existentes, os resultados confirmam a previsão da teoria de pecking order que prevê maior endividamento quando os investimentos excedem os lucros retidos e, novamente, contrariam a previsão da tradeoff estática. Por outro lado, a volatilidade e o investimento não se mostraram significativos.

A inclusão do índice de distribuição de lucros, TP, no painel B produz grandes mudanças nas três alternativas de dividendos, juros sobre o capital próprio e somatório dos dois, $D_{t}, J_{t}$ e $D_{t}+J_{t}$, tornando a volatilidade, $\ln \left(A_{t}\right)$, o investimento, $d A_{t}$, além da lucratividade estatisticamente significativos. Como esperado pela teoria de pecking order a lucratividade continua com o sinal negativo, porém com expressivo aumento nos valores dos coeficientes (de $-0,47$ para $-2,27$ ) e na estatística $t$ (de $-4,65$ erro padrão para $-5,36$ erro padrão), indicando o relacionamento entre a distribuição lucro a lucratividade.

O mesmo sinal negativo para a volatilidade foi encontrado, também, por Silva e Brito (2004). Isso não confirma a previsão teórica de que empresas maiores teriam maior facilidade para se endividar. Por outro lado, os relativamente modestos valores dos coeficientes de volatilidade encontrados $(-0,04$ a $-0,08)$ sugerem uma baixa alavancagem das empresas brasileiras.

Já os investimentos que não eram estatisticamente significativos na forma reduzida tornaram-se altamente significativos (estatística $t$ varia de 0,13 erro padrão para $4,45,4,27$ e 4,39 erro padrão, respectivamente para os dividendos, juros sobre o capital próprio e o somatório desses dois, $D_{t}, J_{t}$ e $D_{t}+J_{t}$ ), confirmando a previsão de que a distribuição de lucros, os investimentos e a alavancagem são estreitamente interligados. Os expressivos valores dos coeficientes indicam o forte relacionamento com a alavancagem. 
Tabela 5 Estimativas da equação 7

\begin{tabular}{|c|c|c|c|c|c|c|c|}
\hline & Int & $V_{t} / A_{t}$ & $\mathrm{ET}_{\mathrm{t}} / \mathrm{A}_{\mathrm{t}}$ & $\operatorname{Ln}\left(A_{t}\right)$ & $\mathrm{dA} / \mathrm{A}_{\mathrm{t}}$ & $\mathrm{TP}_{\mathrm{t}+1}$ & $\mathrm{R}^{2}$ \\
\hline \multicolumn{8}{|l|}{ Painel A } \\
\hline Média & 0,2972 & 0,2210 & $-0,4709$ & $-0,0045$ & 0,0112 & & 0,2647 \\
\hline Estatística t & 3,2295 & 9,0741 & $-4,6562$ & $-0,6264$ & 0,1324 & & 5,4242 \\
\hline \multicolumn{8}{|l|}{$D_{t+1} / A_{t+1}$} \\
\hline \multicolumn{8}{|l|}{ Painel B } \\
\hline Média & 1,3297 & $-0,4066$ & $-2,2793$ & $-0,0865$ & 0,9313 & 5,0324 & 0,3727 \\
\hline Estatística t & 5,4199 & $-2,7371$ & $-5,3687$ & $-4,6959$ & 4,4599 & 4,5646 & 7,8255 \\
\hline \multicolumn{8}{|l|}{ Painel C } \\
\hline Média & 0,0163 & 0,3561 & & 0,0177 & $-0,2250$ & $-1,1437$ & 0,2218 \\
\hline Estatística t & 0,1544 & 7,8278 & & 2,1457 & $-2,6737$ & $-3,5424$ & 4,7973 \\
\hline
\end{tabular}

$J_{t+1} / A_{t+1}$

Painel B

\begin{tabular}{|c|c|c|c|c|c|c|c|}
\hline Média & 0,3832 & 0,2078 & $-2,2793$ & $-0,0458$ & 0,6665 & 5,6896 & 0,3727 \\
\hline Estatística t & 4,0913 & 10,7427 & $-5,3687$ & $-4,2559$ & 4,2783 & 4,5646 & 7,8255 \\
\hline \multicolumn{8}{|l|}{ Painel C } \\
\hline Média & 0,2314 & 0,2164 & & 0,0084 & $-0,1649$ & $-1,2931$ & 0,2218 \\
\hline Estatística t & 2,4482 & 8,2893 & & 1,1439 & $-1,9934$ & $-3,5424$ & 4,7973 \\
\hline
\end{tabular}

$D_{t+1} / A_{t+1}+J_{t+1} / A_{t+1}$

Painel B

\begin{tabular}{l|l|l|l|l|l|l|l}
\hline Média & 0,8855 & $-0,1182$ & $-2,2793$ & $-0,0674$ & 0,8070 & 2,6704 & 0,3727 \\
\hline Estatística t & 5,5614 & $-1,3768$ & $-5,3687$ & $-4,6004$ & 4,3966 & 4,5646 & 7,8255 \\
\hline
\end{tabular}

Painel C

\begin{tabular}{l|c|c|c|c|c|c|c}
\hline Média & 0,1173 & 0,2905 & & 0,0133 & $-0,1968$ & $-0,6069$ & 0,2218 \\
\hline Estatística t & 1,5508 & 9,0480 & & 1,7242 & $-2,3695$ & $-3,5424$ & 4,7973 \\
\hline
\end{tabular}

O valor da empresa continua estatisticamente significativo para os casos de dividendos, $\mathrm{D}_{\mathrm{t}}$, e juros sobre o capital próprio, $\mathrm{J}_{\mathrm{t}}$, com exceção do caso do somatório dos dois, $\mathrm{D}_{t}+\mathrm{J}_{\mathrm{t}}$. Uma possível explicação para esse fato poderia ser o fato de que a oportunidade de crescimento (implícita no valor da empresa) foi captura$\mathrm{da}$, em grande parte, pelos investimentos cujos coeficientes tiveram um expressivo aumento.

A suspeita de colinearidade levou à omissão da lucratividade no painel C o que pro- vocou um aumento na significância da variável valor da empresa (7,82, 8,28 e 9,04 erro padrão para cada um dos casos, respectivamente) e na manutenção de alta significância do índice de distribuição de lucros (3,54 erro padrão para os três casos). Esse resultado confirma a hipótese de que a distribuição de lucros é fortemente influenciada pela lucratividade que também está implícita no valor da empresa. Por outro lado, a volatilidade deixa de ter significância estatística em todos os 
três casos de dividendos, juros sobre o capital próprio e o somatório dos dois, $\mathrm{D}_{\mathrm{t}} \mathrm{J}_{\mathrm{t}}$ e $\mathrm{D}_{\mathrm{t}}+$ J. Já o investimento mostrou-se significativo nos casos de dividendos, $\mathrm{D}_{\mathrm{t}}$, e somatório de dividendos e juros sobre o capital próprio, $\mathrm{D}_{\mathrm{t}}$ $+\mathrm{J}_{\mathrm{t}}$, indicando que a alavancagem é por ela afetada.

Deve ser registrado que as estimativas, na sua forma completa (painel B, incluindo os índices de distribuição de lucros), registram um aumento do $\mathrm{R}^{2}$ (de 0,26 sem TP para 0,37 com TP) como era de se esperar e sugerem que a inclusão da variável do índice de distribuição de lucros, TP, aumenta o poder de explicação da equação. $\mathrm{O}$ inverso ocorre no painel $\mathrm{C}$ com a omissão da variável lucratividade que provoca uma substancial queda do $\mathrm{R}^{2}$ para 0,22 .

De uma forma geral, pode-se dizer que o endividamento e a lucratividade se comportam da forma prevista pela teoria de pecking order. A mesma conclusão não pode ser estendida para a teoria de tradeoff estática que prevê uma relação positiva entre o endividamento e a lucratividade.

\subsection{Hipótese 4}

A hipótese 4 tem o objetivo de testar se as empresas possuem metas de alavancagem e procuram a ela retornar no curto prazo, como prevê a teoria de tradeoff estática. Para esse teste, Fama e French (2002) propuseram uma equação que regride a variação do endividamento contra a meta de alavancagem, o endividamento do período anterior e as variações de lucratividade e de investimento. A velocidade de ajustamento, conforme Fama e French (2002) é dada pelo coeficiente $c_{1}$ da meta de alavancagem. Os resultados são mostrados na Tabela $6 \mathbf{0}$.

As estimativas indicam que a meta de alavancagem (coeficiente $c_{1}$ ) e as variações da lucratividade (coeficiente $c_{3}$ ) são significativos para o ajustamento da dívida em direção à meta de alavancagem. $\mathrm{O}$ sinal negativo da variação da lucratividade é consistente com a previsão de que a alavancagem e a lucratividade são negativamente relacionados. Já o endividamento do ano anterior, embora apresentasse estatística $t$ praticamente igual ao $t$ crítico (2,29 contra o crítico de 2,306), reportou coeficientes negativos, conforme previsto por Fama e French (2002). Esses resultados sugerem um lento ajustamento em direção à meta de alavancagem de cerca de $10 \%$ dado pelo coeficiente $c_{1}$ da meta de alavancagem, confirmando as previsões da teoria de tradeoff estática. Já a variação do investimento (coeficiente $c_{4}$ ) não se mostrou estatisticamente significativa. $O \mathrm{R}^{2}$ de 0,30 encontrado nas

Tabela 6 Estimativas da equação 8

\begin{tabular}{|c|c|c|c|c|c|c|}
\hline & Int & $\mathrm{TL}_{t+1}$ & $L_{t} / A_{t}$ & $d E_{t+1} / A_{t+1}$ & $d A_{t+1} / A_{t+1}$ & $\mathrm{R}^{2}$ \\
\hline \multicolumn{7}{|l|}{$D_{t+1} / A_{t+1}$} \\
\hline Média & 0,0114 & 0,1081 & $-0,0855$ & $-0,2237$ & 0,0721 & 0,3072 \\
\hline Estatística t & 0,4407 & 2,4054 & $-2,2921$ & $-2,4803$ & 0,9839 & 5,6304 \\
\hline \multicolumn{7}{|l|}{$J_{t+1} / A_{t+1}$} \\
\hline Média & 0,0114 & 0,1081 & $-0,0855$ & $-0,2237$ & 0,0721 & 0,3072 \\
\hline Estatística t & 0,4407 & 2,4054 & $-2,2921$ & $-2,4803$ & 0,9839 & 5,6304 \\
\hline \multicolumn{7}{|c|}{$D_{t+1} / A_{t+1}+J_{t+1} / A_{t+1}$} \\
\hline Média & 0,0114 & 0,1081 & $-0,0855$ & $-0,2237$ & 0,0721 & 0,3072 \\
\hline Estatística t & 0,4407 & 2,4054 & $-2,2921$ & $-2,4803$ & 0,9839 & 5,6304 \\
\hline
\end{tabular}


estimativas pode ser considerado respeitável considerando que esse valor costuma ser, tipicamente, baixo nas regressões cross section de empresas individuais como afirmam Fama e French (2002).

Embora Shyam-Sunder e Myers (1999) argumentem que para a teoria de pecking order não existe reversão à média da meta de alavancagem e que, se isso ocorrer, se deve apenas às autocorrelações nas variações do fluxo de caixa, os resultados indicam um lento ajustamento, confirmando a teoria de tradeoff estática. Vale acrescentar, ainda, a constatação, na pesquisa de Graham e Harvey (2001), de que os diretores financeiros das empresas afirmaram ter metas de alavancagem, porém o seu atingimento não é prioritário.

As estimativas feitas para as equações que tinham os juros sobre o capital e o somatório dos juros e dividendos, mostraram os mesmos resultados reportados na Tabela 6 com variações nos coeficientes apenas a partir da sétima casa decimal, razão pela qual não é aqui reportada. Isso sugere que os dividendos e juros sobre o capital próprio desempenham o mesmo papel no que se refere ao ajustamento da dívida em direção à meta de alavancagem.

\section{CONCLUSÃO}

Baseado no estudo de Fama e French (2002), este artigo teve por objetivo analisar as relações conjuntas da estrutura de capital, dividendos e juros sobre o capital próprio das empresas brasileiras para o período de 1995 a 2004, comparando os seus resultados com as previsões estabelecidas pelas teorias de tradeoff estática e pecking order. Em função da especificidade da legislação brasileira no que diz respeito às diferentes formas de distribuição de lucros, este artigo analisou, além da distribuição de dividendos, também a remuneração por meio dos juros sobre o capital próprio.

Os resultados confirmaram as previsões da teoria de pecking order de que a distribuição de lucros varia positivamente com a lucratividade e negativamente com o investimento, porém o mesmo não ocorreu com as oportunidades de crescimento que mostraram uma relação negativa com a distribuição de lucros. Além disso, não foram encontradas evidências de que há ajustamento nas distribuições de lucros para absorver as variações de curto prazo do investimento, confirmando a premissa de Lintner (1956) de que a administração das empresas reluta em alterar a política de distribuição de lucros em razão da sinalização implícita que tal alteração pode- ria enviar aos investidores. Dessa forma, esses resultados confirmam a previsão da teoria de pecking order de que os dividendos são "fixos" e eventuais variações de investimentos são absorvidas pelo endividamento. Outro resultado observado foi a relação negativa entre a alavancagem e a lucratividade, que confirma a previsão da teoria de pecking order de que as empresas utilizam os lucros retidos para financiar os seus investimentos e só recorrem ao endividamento depois de esgotados os recursos internos. Por outro lado, os resultados encontrados não confirmam a teoria de tradeoff estática que prevê uma relação positiva entre elas motivada pelos benefícios fiscais, custos de agência e menores custos de falência das empresas lucrativas. Da mesma forma, os resultados confirmaram a previsão de relação positiva e estatisticamente significativa entre a alavancagem e os investimentos. Por fim, os resultados sugerem que as empresas possuem metas de alavancagem, embora seja lenta a velocidade de ajustamento em direção a elas. Isso não só confirma a previsão da teoria de tradeoff estática, como corrobora os resultados da pesquisa de Graham e Harvey (2001), cuja pesquisa sugere que as metas existem, porém alcançá-las não é prioridade para as empresas. 
Uma constatação relevante é que a distribuição de lucros (dividendos e juros sobre capital próprio somados) no Brasil ainda é muito baixa comparada com a americana, não obstante a existência da obrigatoriedade de distribuição de lucros e a vantagem fiscal dos juros sobre o capital próprio, porém, é digno de registro o aumento desse índice em comparação com os resultados encontrados por Silva e Brito (2004) para o período de 1995 a 2001 de 0,11. Uma possível explicação para esse aumento da distribuição de lucros poderia ser a crescente utilização dos juros sobre o capital próprio, especialmente, a partir de 1997, além das exigências maiores dos investidores em relação à governança corporativa. Entre essas exigências destacam-se os direitos dos acionistas minoritários, o direito ao tag along nas operações de venda de controle e o cumprimento da distribuição de lucros na forma de dividendos e/ou juros sobre o capital próprio.

Como previsto pelas teorias de tradeoff estática e pecking order, a lucratividade é a variável de maior peso e influencia fortemente tanto a distribuição de lucros como a alavancagem como demonstraram os testes realizados. Os testes que omitem a lucratividade parecem transferir para o valor da empresa, $V_{t}$, o papel representado pela lucratividade. Isso corrobora a idéia de que o $V_{t}$, além de refletir as oportunidades de crescimento, também reflete a lucratividade dos ativos existentes.

O presente artigo apresenta, pelo menos, duas importantes limitações que poderiam ser resolvidas em estudos futuros. A primeira limitação diz respeito ao período da amostra, que vai de 1995 a 2004. O período foi intencionalmente escolhido em função da relativa estabilidade econômica trazida pelo Plano Real em 1994. A ampliação desse período com a inclusão de anos anteriores ao Plano Real poderia apresentar resultados diferentes em função da tributação dos dividendos, não realizada a partir de 1996. Do ponto de vista econométrico, esse efeito poderia ser contro- lado com a utilização de uma variável dummy que discriminasse as observações anteriores e posteriores a 1995.

A segunda limitação diz respeito ao tratamento dado à questão da endogeneidade. Separadamente, são estudados os determinantes do nível distribuição de lucros (dividendos e juros sobre o capital próprio) e do nível de endividamento. No primeiro caso, assume-se que o endividamento seja uma variável exógena e que influencie o nível de distribuição de lucros. Já no segundo caso, assume-se o contrário, ou seja, que a distribuição de lucros seja exógena e que explique o endividamento. Essas relações unidirecionais, entretanto, não são necessariamente as únicas possíveis. Tanto o endividamento como a distribuição de lucros também podem possuir uma característica endógena. Pela teoria do pecking order, por exemplo, as empresas que persistentemente façam grandes investimentos tenderiam a apresentar alto endividamento. Entretanto, o alto nível de endividamento poderia ser amenizado com a redução do pagamento de dividendos (FAMA; FRENCH, 2002). Por esse ponto de vista, os dividendos influenciariam o nível de endividamento. Num contexto diferente, em que a empresa tenha poucas oportunidades de investimento, a mesma poderia aumentar o pagamento de dividendos, aumentando proporcionalmente o nível de dívidas, para mitigar potenciais problemas de agência, como sugerido por Jensen (1986). Nesse contexto, o baixo nível de endividamento (isto é, o alto nível de capital próprio) é que influenciaria a decisão de se pagar mais dividendos.

Apesar da importância da discussão da endogeneidade, essa análise está fora do escopo do presente estudo, uma vez que este se propõe a reproduzir o modelo de Fama e French (2002) no mercado brasileiro. Para estudos futuros, sugere-se a aplicação de técnicas estatísticas adequadas para o tratamento da endogeneidade como, por exemplo, o modelo de equações simultâneas. 
Concluindo: a expectativa desta pesquisa é que ela possa contribuir de alguma forma para aumentar a compreensão tanto da estrutura de capital como da distribuição de lucros no Brasil. Ressalte-se, porém, que os seus resultados não devem ser generalizados para todas as empresas, dadas as limitações de dados e o não atendimento às exigências estatísticas de aleatoriedade existentes nos trabalhos deste tipo.

\section{Referências}

COCHRANE, J. H. Asset pricing. Revised Edition.

Princeton University Press, 2005.

FAMA, E. F.; BABIAK, H. Dividend policy: an empirical analysis. Journal of the American Statistical Association, v. 63, n. 324, p. 1132-1161, Dec. 1968.

; FRENCH, K. R. Testing tradeoff and pecking order predictions about dividends and debt. The Review of Financial Studies, New York, v. 15, n. 1 p. 1-33, Mar. 2002.

; MacBETH, J. D. Risk, return and equilibrium: empirical tests. Journal of Political Economy, Chicago, v. 81, n. 3, p. 607-636, May/June 1973.

GRAHAM, J. R.; HARVEY, C. R. The theory and practice of corporate finance: evidence from the field. Journal of Financial Economics, Amsterdam, v. 60, n. 2/3, p. 1-53, 2001.

JENSEN, M. C. Agency costs of free cash flow, corporate finance and takeovers. American Economic Review, Nashville, v. 76, n. 2, p. 323-329, May 1986.

LINTNER, J. Distribution of incomes of corporations among dividends, retained earnings and taxes. The
American Economic Review, Washington, v. 46, n. 2, p. 97-113, May 1956.

MILLER, M. H.; MODIGLIANI, F. Dividend policy, growth and the valuation of shares. Journal of Business, v. 34, n. 4, p. 411-433, Oct. 1961.

MODIGLIANI, F.; MILLER, M. The cost of capital, corporation finance and the theory of investment. The American Economic Review, Nashville, v. 48, n. 3, June 1958.

Corporate income taxes and the cost of capital: a comment. The American Economic Review, Nashville, v. 53, n. 3, p. 433-443, June 1963.

SHYAM-SUNDER, L.; MYERS, S. C. Testing static tradeoff against pecking order models of capital structure. Journal of Financial Economics, v. 51, n. 2, p. 219-244, Feb. 1999.

SILVA, J. C.; BRITO, R. D. Testando as previsões de trade-off e pecking order sobre dividendos e dívida para o Brasil. Finance Lab Working Paper - FLWP 2004.07. IBMEC. 2004. Disponível em: <http://www.ibmecsp.edu. br>. Acesso em: 20 out. 2005. 